\title{
Paediatric invasive long-term ventilation - A ten-year review
}

\author{
Aoibhinn Walsh ${ }^{1}$, Mairead Furlong ${ }^{1}$, Paul McNally ${ }^{1}$, Ruth O’Reilly ${ }^{1}$, Sheila Javadpour ${ }^{1}$, \\ and Des Cox ${ }^{1}$ \\ ${ }^{1}$ Children's Health Ireland at Crumlin
}

January 21, 2021

\begin{abstract}
Background and objective: The number of children with complex physical and developmental pathologies, including chronic respiratory insufficiency, surviving and growing beyond early childhood continues to rise. No study has examined the clinical pathway of children on invasive LTMV in an Irish setting. Our data over a 10-year period was reviewed to see if our demographics and outcomes are in line with global trends. Methods: Children's Health Ireland (CHI) at Crumlin, Dublin is Ireland's largest tertiary paediatric hospital. A retrospective review analysed data from children in our centre commenced on LTMV via a tracheostomy over 10 years $(2009-2018)$. This data was subdivided into two epochs for statistical analysis of longitudinal trends. Results: Forty-six children were commenced on LTMV from 2009 to 2018. Many had complex medical diagnoses with associated co-morbidities. Far less children, 30.4\% ( $\mathrm{n}=14)$ commenced on LTMV in the latter half of the 10-year period, they also fared better in all aspects of their treatment course. Focusing solely on children who have needed LTMV over this timeframe has enabled us to isolate trends specific to this cohort. Less patients commenced LTMV on a year on year basis, and for those that require tracheostomy and LTMV, their journey to decannulation tends to be shorter. Conclusion: Over the period reviewed, less patients over time necessitated long-term invasive therapy and those patients are being weaned and decannulated with ever more success. This has implications in terms of predicting numbers transitioning to adult services and allocation of hospital and community care resources.
\end{abstract}

\section{Hosted file}

Pediatric Pulmonology Article Submission Final.pdf available at https://authorea.com/users/ 390999/articles/505205-paediatric-invasive-long-term-ventilation-a-ten-year-review 


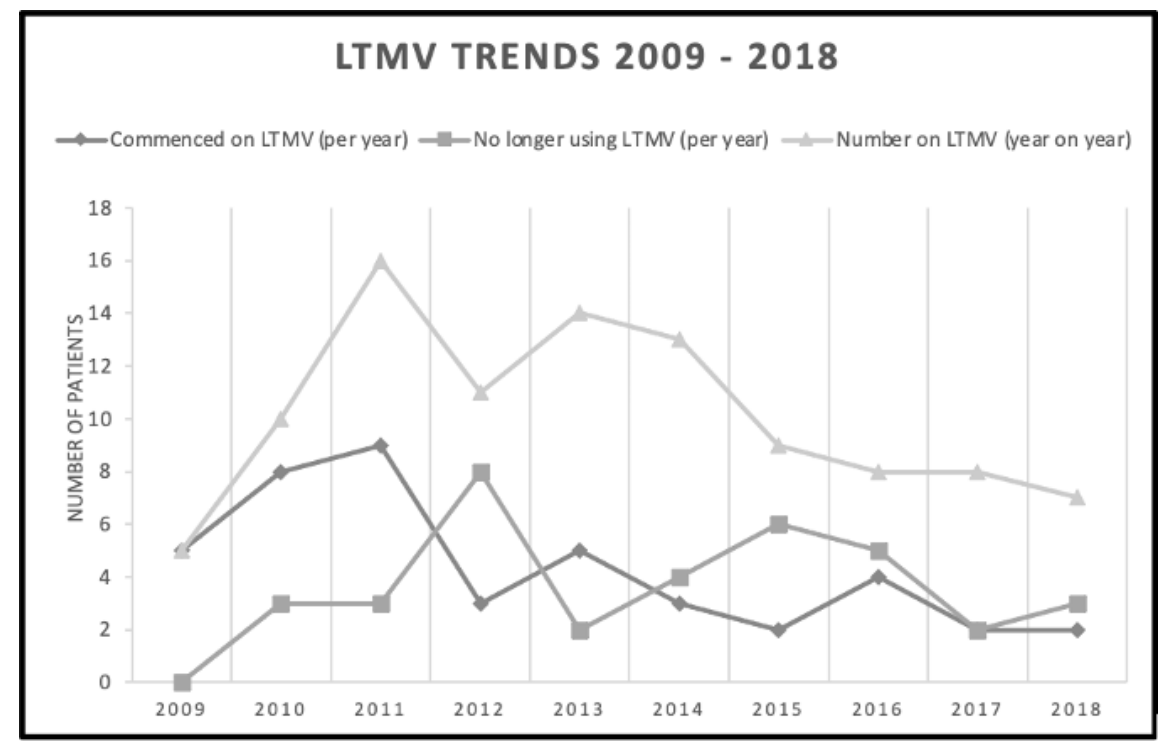

\section{Hosted file}

Table 12 and 3 PedPulmonology.pdf available at https://authorea.com/users/390999/articles/ 505205-paediatric-invasive-long-term-ventilation-a-ten-year-review 